\title{
МАТЕМАТИЧЕСКАЯ МОДЕЛЬ ПОДГОТОВКИ КАДРОВ ДЛЯ ИННОВАЦИОННОГО РАЗВИТИЯ САМАРСКОЙ ОБЛАСТИ
}

\section{MATHEMATICAL MODEL OF PERSONNEL TRAINING FOR INNOVATIVE DEVELOPMENT OF SAMARA REGION \\ Ya. Stelmakh \\ T. Kochetova}

Summary: This research is devoted to the personnel training for the innovative development of the region at the Samara State Technical University. Based on the analysis of scientific literature, indicators were identified by which the authors assess the university's contribution to the innovative development of the region. The indicators are divided into three main blocks: the scientific product of the Samara region, the innovative potential of the university, the readiness to generate and implement innovations. To assess the indicators, the data of Samarastat and the official statistics of the university were used, which allows characterizing the activities of the university and the innovative development of the Samara region by analyzing statistical data, the growth of which can be interpreted as a result of a positive level of innovative development of the region. A mathematical model of personnel training in the form of a Cobb-Douglas production function and a formula for determining the need for personnel for the innovative development of a region have been built.

Keywords: mathematical model, innovative development, region, university, personnel training.

\author{
Стельмах Янина Геннадьевна \\ К.n.н., доцент, Самарский государственный \\ технический университет \\ yaninastelmah@mail.ru \\ Кочетова Татьяна Николаевна \\ К.п.н., доцент, Самарский государственный \\ технический университет \\ tnkochetova@list.ru
}

Аннотация: Данное исследование посвящено подготовке кадров для инновационного развития региона в Самарском государственном техническом университете. На основе анализа научной литературы, были выделены показатели, по которым авторы оценивают вклад университета в инновационное развитие региона. Показатели разбиты на три основных блока: научный продукт Самарской области, инновационный потенциал вуза, готовность к генерации и внедрению инноваций. Для оценки показателей использованы данные Самарастат и официальная статистика университета, что позволяет характеризовать деятельность вуза и инновационное развитие Самарской области по анализу статистических данных, рост которых можно трактовать как результат позитивного уровня инновационного развития региона. Построена математическая модель подготовки кадров в форме производственной функции Кобба-Дугласа и формула для определения потребности в кадрах для инновационного развития региона.

Ключевые слова: математическая модель, инновационное развитие, регион, университет, подготовка кадров.
$\Pi$ овышение уровня инновационной активности производства в Самарской области и создание новых высокотехнологичных бизнесов в разных сферах экономики является одним из важнейших направлений региональной инновационной политики. Ключевым факторам инновационного развития Самарской области является научно-технический потенциал, который формируется из показателей финансового и человеческого ресурса обеспечения НИОКР, патентной и публикационной активности, количества инноваций в компаниях [1, с. 44], увеличение деловой активности в бизнесе и повышение инвестиционного обеспечения при создании инновационных кластеров [2, с.144], нормативного регулирования деятельности организаций [3, с. 24]. Для повышения эффективности процесса инновационного развития и поддержки компаний, которые осуществляют деятельность в соответствии с приоритетными направлениями модернизации экономики России в Самарской области создана развитая инновационная инфраструктура: технопарк «Жигулевская долина»; существует особая экономическая зона промышленно-производ- ственного типа «Тольятти»; на базе Фонда «Региональный центр развития предпринимательства Самарской области» организован центр поддержки экспорта и т.д. Однако до настоящего времени не удается кардинально повысить инновационную активность Самарской области. Исследование звеньев, составляющих инновационное развитие, позволяет разработать программу социально-экономического развития региона и эффективно использовать местные ресурсы для улучшения качества жизни населения области и страны в целом. Таким образом, ведение мониторинга инновационной деятельности Самарской области и осуществление прогнозов обеспечивает принятие рациональных решений. Методы прогноза на основе детального индивидуального анализа, как правило, требуют больших временных затрат, поэтому удобно использовать математические модели, в которых регион представлен как сложная управляемая система. В современных условиях для решения поставленных задач инновационного развития области, обеспеченность региона высококвалифицированными кадрами значительно возрастает. 
Самарский государственный технический университет (СамГТУ) готовит кадры для большинства приоритетных направлений социально-экономического развития региона, поэтому поддержка талантливых студентов, подготовка их к инновационной деятельности и закрепление подготовленных выпускников на территории Самарской области необходимы для эффективного использования интеллектуального человеческого потенциала [4]. Недостаточная ориентация системы высшего образования региона на потребности инновационного сектора экономики и невысокая на мировом рынке образования конкурентоспособность вузовских программ обуславливают снижение темпов развития наукоемких отраслей экономики и требуют системного подхода в решении этих проблем. Таким образом, необходимость корректировки процесса образовательной деятельности с учетом потребности специалистов в том или ином направлении перспективного спроса для инновационного развития региона обусловило актуальность использования экономико-математической модели для прогнозирования потребительского рынка и корректировки подготовки специалистов в вузе [5, с. 65]. При изучении статистических данных обратим внимание на информацию о количестве выпускников вуза, чтобы выявить их влияние на основные показатели уровня инновационного развития. Учитывая выше сказанное, обозначим цель нашего исследования: построить математическую модель, позволяющую определить вклад опорного вуза в инновационное развитие региона.

Анализ литературы показал, что существуют различные подходы к измерению уровня инновационного развития и вклада университета в инновационное развитие региона. Исследователи Е.В. Огурцова, О.В. Перфильева и А.А. Фирсова предлагают оценку вклада университета в инновационное развитие региона определять следующими факторами: уровнем инновационного потенциала, уровнем инновационного развития региона, а также уровнем интеллектуального потенциала университета, которые предлагают рассчитывать, используя официальную статистику, а далее использовать методику, которая позволяет проводить сравнение экономических систем на основе анализа Inputs и Outputs и недискретных параметров функционирования систем [6, с. 53]. Г.А. Хмелева и Н.М. Тюкавкин провели анализ современных зарубежных и методических подходов к оценке инновационного развития регионов и определили, что в основном исследователи группируют наборы показателей по принципу выделения определяющих факторов и итогом оценочных процедур является интегральное значение инновационного потенциала. [7, с. 23] Мы за основу возьмем методику оценки индекса инновационного развития регионов России, разработанную М.И. Бортник, Г.И. Сенченя, Н.Н. Михеевой, А.А. Здуновым, П.А. Кадочниковым и А.В. Сорокиной, которая состоит из трех блоков: потенциал в создании инноваций; потенциал в коммерциализации инноваций; результативность инновационной политики региональных властей $[8$, с. 28].

Учитывая, цель данного исследования, обоснуем выбор показателей инновационного развития региона при помощи анализа статистических данных. Формально выразим, как уровень инновационного развития влияет на основные показатели региона. В целом, соглашаясь с предложенной авторами методикой [8, с. 28], и учитывая, что научный продукт Самарской области (потенциал региона в создании инноваций) выделим первый показатель - число субъектов в регионе с высшим образованием, занятых не только в региональной экономике, но и на проведении исследований $\left(\mathrm{x}_{1}\right)$, второй показатель число зарегистрированных патентов $\left(\mathrm{X}_{2}\right)$. Под инновационным потенциалом вуза (потенциал вуза в создании инноваций) будем считать, во-первых, число выпускников $\left(\mathrm{y}_{1}\right)$ и, во-вторых, количество методических и научных работ студентов и преподавателей вуза $\left(\mathrm{y}_{2}\right)$. Следующий блок - готовность к генерации и внедрению инноваций (потенциал в коммерциализации инноваций), который отражает возможности региона и вуза в производстве инновационной продукции. В нашей модели к основному показателю, который характеризует потенциал в коммерциализации инноваций, будут относиться расходы на проведение НИОКР в Самарской области $\left(\mathbf{x}_{3}\right)$. Последний блок - продуктивность инноваций (результативность инновационной политики региона) выделим три показателя: первый - валовой региональный продукт $\left(\mathrm{x}_{4}\right)$, второй - это число используемых передовых производственных технологий $\left(\mathrm{X}_{5}\right)$, и последний показатель это затраты на прикладные исследования $\left(\mathrm{X}_{6}\right)$.

При разработке экономико-математической модели инновационного развития региона исследователи используют различные подходы. Так, Д.Л. Напольский [9, с. 4], методологию исследования основывает на применении математического моделирования с элементами системного анализа процессов развития экономических систем и его модель мультикластерного развития основана на интеграции смежных видов экономической деятельности, на базе выделенных автором технологий. Соглашаясь с автором, стоит отметить, что выделенный перечень технологий в зависимости от цели исследований требует корректировки. Ученые Л.А. Сосунова и Е.А. Серпер [10, с. 95] выполняют экономико-математическое моделирование инновационного развития экономики на основе производственной функции и в своей работе определяют коэффициенты эластичности модели и дают оценку влияния фактора научно-технического процесса. Н.Н. Киселева и Н.П. Иванов перспективным методом считают построение модифицированной функции Кобба-Дугласа с использованием модели Я. Тинбергеа $[11$, c. 78]. При построении математической модели подготовки кадров будем применять производственную 
функцию и, выполнив преобразования, получим формулу для определения потребности в кадрах для инновационного развития региона.

В качестве входных параметров мы принимаем следующие показатели СамГТУ: выпуск студентов СамГТУ -у ${ }_{1}$

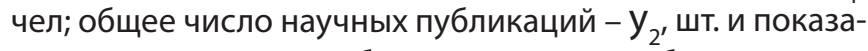
тели региона: число субъектов с высшим образованием, занятых не только в региональной экономике, но и на проведении исследований $\mathrm{x}_{1}$ чел; число зарегистрированных патентов $\mathrm{X}_{2}$ единиц; расходы на проведение НИОКР в Самарской области $\mathrm{X}_{3}$ млрд. руб.; валовой региональный продукт Самарской области - Z млрд. руб.; количество используемых передовых производственных технологий $-\mathrm{X}_{5}$ единиц; внутренние текущие затраты на прикладные исследования - Х млн. руб. $[12,13]$. Парные коэффициенты результата с каждым фактором соответственно позволяют сделать вывод о том, что все факторы оказывают заметное влияние на результат. Рассчитав матрицу парных коэффициентов корреляции, построим математическую модель, где в качестве входных параметров примем следующие показатели опорного вуза Самарской области: выпуск студентов СамГТУ - у ${ }_{1}$ чел.; общее число научных публикаций $-\mathrm{y}_{2}$, шт.; расходы на проведение НИОКР в Самарской области $\mathrm{X}_{3}$ млрд. руб.; и число зарегистрированных патентов $\mathrm{X}_{2}$ единиц.

При моделировании потребности специалистов для инновационного развития региона будем использовать метод построения математических моделей в виде неоднородной производственной функции Кобба-Дугласа [14] (1).

$$
\hat{Z}(t)=A \cdot \mathrm{y}_{1}(\mathrm{t})^{\chi} \cdot \mathrm{y}_{2}(\mathrm{t})^{\kappa} \cdot \mathrm{x}_{2}(\mathrm{t})^{\varphi} \cdot \mathrm{x}_{3}(\mathrm{t})^{\rho},
$$

где $\mathrm{Z}(\mathrm{t})$ - валовой региональный продукт Самарской области; $\chi, \kappa, \varphi, \rho$ - характеристики эффективности использования ресурса - показатели эластичности; $\chi$ - для фактора $\mathrm{y}_{1}(\mathrm{t}) ; \kappa$ - для фактора $\mathrm{y}_{2}(\mathrm{t}) ; \varphi$ - для фактора $\mathrm{x}_{2}(\mathrm{t})$ ; $\rho$ - для фактора $\mathrm{x}_{3}(\mathrm{t}) ; \mathrm{A}$ - масштабирующий коэффициент преобразования.

Согласно методу наименьших квадратов оценки параметров $A, \chi, \kappa, \varphi, \rho$ найдем из условия минимизации функционала - суммы квадратов отклонения значений $\hat{Z}$ от исходных данных $Z(t)$ [15]. Далее, рассчитав коэффициент множественной корреляции и коэффициент множественной детерминации можно установить о наличии связи. Оценку надежности уравнения регрессии в целом и коэффициента множественной корреляции можно провести с использованием F-критерия Фишера.

Функцию потребности специалистов для инновационного развития региона можно определить как обратную производственной функции, заданной в краткосроч- ный период. Прологарифмировав обе части функции (1), получим зависимость:

$$
\ln \hat{Z}(t)=\ln A+\chi \cdot \ln \mathrm{y}_{1}(\mathrm{t})+\kappa \cdot \ln \mathrm{y}_{2}(\mathrm{t})+\varphi \cdot \ln \mathrm{x}_{2}(\mathrm{t})+\rho \cdot \ln \mathrm{x}_{3}(\mathrm{t}),(2)
$$

Выразив из зависимости (2) выпуск студентов СамГТУ $\mathrm{y}_{1}$, получим формулу (3) позволяющую определить потребность в кадрах для инновационного развития региона:

$\ln \mathrm{y}_{1}(\mathrm{t})=\alpha+\beta \ln \hat{\mathrm{Z}}(\mathrm{t})+\gamma \cdot \ln \mathrm{y}_{2}(\mathrm{t})+\delta \cdot \ln \mathrm{x}_{2}(\mathrm{t})+\lambda \cdot \ln \mathrm{x}_{3}(\mathrm{t}),(3)$

где коэффициенты при показателях в формуле (3):

$$
б=-\frac{\ln A}{\chi}, \mathrm{B}=\frac{1}{\chi}, \Gamma=-\frac{\kappa}{\chi}, \text { д }=-\frac{\varphi}{\chi}, \pi=-\frac{\rho}{\chi} .
$$

Коэффициенты б, в, г, д, л могут принимать как положительные, так и отрицательные значения, так как они показывают характер влияния показателей.

По построенной модели, можно выполнить прогноз и планировать прием в вуз для обеспеченности области высококвалифицированными кадрами, которые повысят уровень инновационнной активности производства и будут способствовать созданию новых высокотехнологичных бизнесов в разных сферах экономики Самарской области.

Использование математической модели на определение степени влияния системы высшего образования на основные показатели инновационного развития региона, поможет определить верное направление в системе подготовки конкурентноспособных кадров для предприятий и организаций реального сектора экономики Самарской области, и позволит вовремя произвести необходимые изменения для принятия правильного решения [16]. Данные, которые можно получить, используя указанную математическую модель можно использовать также для оценки эффективности инновационной деятельности университетов и при построении рейтингов.

Разработка данного метода оценки уровня инновационного развития региона и построение математической модели для прогнозирования потребительского рынка и корректировки подготовки специалистов в вузе позволит не только осуществлять оценку вклада опорного вуза в развитие области и планировать прием студентов, но и изучать различные аспекты деятельности вуза и более эффективно осуществлять инновационную политику в регионе. Так, например, результаты полученного корреляционного анализа по данным Самарастат и официальной статистики университета, позволяют сделать вывод, о том, что общее число научных публикаций сотрудников и студентов 
высшего образовательного учреждения, оказывает заметное влияние на выделенные нами показатели инновационного развития региона, что говорит о необ- ходимости заинтересовать научно-исследовательской деятельностью и привлекать к разработкам и исследованиям студентов, начиная уже с первых курсов [17].

\section{ЛИТЕРАТУРА}

1. Подборнова Е.С. Характеристика инновационной деятельности Самарской области // Вестник Самарского университета. Экономика и управление. 2019. — Т. 10. № 1. - С. 43-47.

2. Макаров Н.В., Квон Г.М. Поддержка и развитие инновационных кластеров в России // Казанский вестник молодых учёных. 2017. №3 (3)., С.142-148.

3. Гудкова А.А. Инновационная инфраструктура в деятельности хозяйственных обществ (партнерств) научных образовательных организаций/ Гудкова А.А., Майданник 0.В., Плиева 3.Р., Турко Т.И. // Инновации. СПбГЭТУ «ЛЭТИ». №2 (232), 2018. С. 24-36.

4. Стельмах Я.Г. Особенности математической подготовки студентов академического бакалавриата. // Самарский научный вестник. 2016. №2 (15). С.185-189.

5. Егоров Н.Е. Вопросы подготовки кадров для инновационного развития экономики регионов Дальнего Востока России // Инновации. СПбГЭТУ «ЛЭТИ». №6 (188), 2014. С. 65-67.

6. Огурцова Е.В. Показатели оценки вклада университета в инновационное развитие региона / Е.В. Огурцова, О.В. Перфильева, А.А. Фирсова // Университетское управление: практика и анализ. Том 21, №4, 2017. С. 53-62.

7. Хмелева Г.А. Современные методические подходы к оценке инновационного развития регионов /Хмелева Г.А., Тюкавкин Н.М. // Вестник Самарского муниципального института управления. 2016. № 2. С. 18-26.

8. Бортник М.И. Система оценки и мониторинга инновационного развития регионов России / М.И. Бортник, Г.И. Сенченя, Н.Н. Михеева и др. // Инновации. СПбГЭТУ «ЛЭТИ». № 9 (167), 2012.С. 48-61.

9. Напольских Д.Л. Экономико-математическое моделирование территориального развития на основе формирования кластеров рационального природопользования // Тренды и управление. - 2018. - № 3. - С. 1 - 13.

10. Сосунова, Л.А. Экономико-математическое моделирование инновационного развития региональной экономики / Л.А. Сосунова, Е.А. Серпер// - Вестник СГЭУ, 2010, № 7 (69). - 90-96 c.

11. Киселева Н.Н. Оценка уровня инновационного развития региона / Н.Н. Киселева, Н.П. Иванов // - Terra Economicus, 2013, Том 11, выпуск 2-2, 76-79 с.

12. Самарский статистический ежегодник. 2017: Стат. сб. Самара: Самарастат, 2017. 346 с.

13. Самарский статистический ежегодник. 2019: Стат. сб. Самара: Самарастат, 2019. 355 с.

14. Клейнер Г.Б. Производственные функции: Теория, методы, применение. - М.: Финансы и статистика, 1986. - 239с.

15. Елисеева И.И. Эконометрика. М. Проспект. 2009г. - 288с.

16. Кочетова Н.Г. Критерии и показатели готовности выпускников технического вуза к профессиональной деятельности / Кочетова Н.Г., Стельмах Я.Г., Кочетова Т.Н. // Самарский научный вестник. 2020. Т.9. №2(31). С.244-248.

17. Стельмах Я.Г. Активизация исследовательской деятельности студентов при изучении математики // Вестник Самарского государственного технического университета. Серия «Психолого-педагогические науки». № 1 (21). 2014. С. 166-173. 